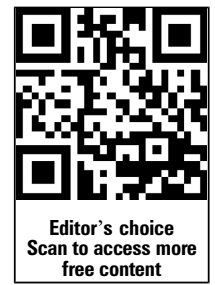

- Additional material is published online only. To view please visit the journal online (http://dx.doi.org/10.1136/ thoraxjnl-2013-203744).

For numbered affiliations see end of article.

Correspondence to Dr Aude Lacourt, ISPED ESSAT, 146 rue leo saignat, Bordeaux 33076, France:

aude.lacourt@

isped.u-bordeaux2.fr

Received 18 April 2013 Revised 14 January 2014 Accepted 15 January 2014 Published Online First 7 February 2014
CrossMark

To cite: Lacourt $A$, Gramond C, Rolland P, et al. Thorax 2014;69:532-539.

\title{
Occupational and non-occupational attributable risk of asbestos exposure for malignant pleural mesothelioma
}

\author{
A Lacourt, ${ }^{1,2}$ C Gramond, ${ }^{1,2}$ P Rolland, ${ }^{3,4}$ S Ducamp, ${ }^{3,4}$ S Audignon, ${ }^{1,2}$ P Astoul, ${ }^{5}$ \\ S Chamming's, ${ }^{6}$ A Gilg Soit $\| g_{1}^{4,7}$ M Rinaldo, ${ }^{1,2}$ C Raherison, ${ }^{1,2} \mathrm{~F}$ Galateau-Salle, ${ }^{4,8}$ \\ E Imbernon, ${ }^{3,7}$ J C Pairon, ${ }^{6,9}$ M Goldberg, ${ }^{7}$ P Brochard ${ }^{1,2}$
}

\begin{abstract}
Objectives To estimate the proportion of pleural mesothelioma cases that can be attributed to asbestos exposure in France including non-occupational exposure. Methods A population-based case-control study including 437 incident cases and 874 controls was conducted from 1998 to 2002. Occupational and nonoccupational asbestos exposure was assessed retrospectively by two expert hygienists. ORs of pleural mesothelioma for asbestos-exposed subjects compared to non-exposed subjects, and population-attributable risk (ARp) of asbestos exposure were estimated using a conditional logistic regression.

Results A clear dose-response relationship was observed between occupational asbestos exposure and pleural mesothelioma ( $\mathrm{OR}=4.0(99 \% \mathrm{Cl} 1.9$ to 8.3$)$ for men exposed at less than $0.1 \mathrm{f} / \mathrm{mL}$-year vs $67.0(99 \% \mathrm{Cl}$ 25.6 to 175.1) for men exposed at more than $10 \mathrm{f} / \mathrm{mL}$-year). The occupational asbestos ARp was $83.1 \%(99 \% \mathrm{Cl}$

\section{Key messages}

What is the key question?

- What is the overall impact of asbestos exposure including non-occupational exposure on pleural mesothelioma?

What is the bottom line?

- Occupational asbestos exposure explains less than half the pleural mesothelioma cases among women, thus, there is a need to quantify the impact of non-occupational asbestos exposure for pleural mesothelioma.

Why read on?

- This study provides insights regarding non-occupational exposure impact in pleural mesothelioma occurrence, especially among women.
\end{abstract} $74.5 \%$ to $91.7 \%)$ for men and $41.7 \%(99 \% \mathrm{Cl} 25.3 \%$ to $58.0 \%$ ) for women. A higher risk of pleural mesothelioma was observed in subjects nonoccupationally exposed to asbestos compared to those never exposed. The non-occupational asbestos ARp for these subjects was $20.0 \%(99 \% \mathrm{Cl}-33.5 \%$ to $73.5 \%)$ in men and $38.7 \%(99 \% \mathrm{Cl} 8.4 \%$ to $69.0 \%)$ in women. When considering all kinds of asbestos exposure, ARp was $87.3 \%$ (99\% Cl $78.9 \%$ to $95.7 \%)$ for men and $64.8 \%(99 \% \mathrm{Cl} 45.4 \%$ to $84.3 \%)$ for women.

Conclusions Our study suggests that the overall ARp in women is largely driven by non-occupational asbestos exposure arguing for the strong impact of such exposure in pleural mesothelioma occurrence. Considering the difficulty in assessing domestic or environmental asbestos exposure, this could explain the observed difference in ARp between men and women.

\section{INTRODUCTION}

Malignant mesothelioma is a rare tumour mostly located in the pleura and associated with poor survival. To date, asbestos and erionite fibres are the only recognised risk factors for pleural mesothelioma. ${ }^{12}$

Asbestos had been extensively used in many industries all around the world, and was progressively banned in most industrialised countries, with such action taking place first in Europe in the 1980s and specifically in 1997 in France. However, asbestos is still produced and used in many countries, most of them being developing countries. This massive use of asbestos fibres has been correlated with an increase in the incidence of asbestos-related diseases and, in particular, pleural mesothelioma. ${ }^{3}$

The causal relationship between occupational asbestos exposure and pleural mesothelioma is already well established, ${ }^{4-13}$ and it is estimated that approximatively $80 \%$ of male cases may be attributed to occupational asbestos exposure. Although the role of non-occupational asbestos exposure (para-occupational, domestic or environmental) in the occurrence of pleural mesothelioma has already been demonstrated, ${ }^{14-16}$ there is a need to quantify the risk attributable to such exposure, especially in women in whom only $40 \%$ of cases can be explained by occupational exposure. ${ }^{10}$ Knowledge about overall asbestos exposure (occupational and/ or non-occupational exposure) attributable risk could provide further information regarding the aetiology of pleural mesothelioma and could be useful to help authorities for prevention in situations where asbestos-containing materials still persist in developed countries, and where asbestos is still in use in developing countries.

In France, the National Mesothelioma Surveillance Program (PNSM) was set up in 1998 
to provide relevant information on the health effects of asbestos exposure on the French population. It relies on the exhaustive recording of all incident primary pleural tumours in specified districts. ${ }^{17}$

The present study reports the occupational, non-occupational and overall asbestos exposure-attributable risk for pleural mesothelioma from a population-based case-control study carried out between 1998 and 2002 .

\section{MATERIALS AND METHODS Study design}

The study design was previously reported in detail. ${ }^{18}$ Cases were identified through the PNSM from 1998 to 2002 and certified by a standardised diagnostic confirmation procedure. ${ }^{17}$ Two controls, selected from the general population, were matched with cases for sex, age ( \pm 5 years) and district of residence. Participation rates of cases and controls were $61.1 \%$ and $20.8 \%$, respectively.

Trained interviewers administered a standardised questionnaire to each subject. Only subjects alive at the time of the interview were included. Information about lifetime residential, educational and occupational history (including details on job tasks and do-it-yourself activities), demographic characteristics including the socioeconomic category defined by the last occupation held, previous respiratory diseases, occupations of partners and parents, and family cancer history were collected. A more specific part of the questionnaire focused on specific lifetime situations that might have involved asbestos exposure, for example, spraying fibres, asbestos cement disposal and removal, other insulation with asbestos-containing products (sheets, ropes, gaskets, etc), brake and clutch repairs, and washing asbestos-contaminated clothes. Additional questions concerned other suspected risk factors such as ionising radiations, and man-made mineral fibres (glass fibres and mineral wool, refractory ceramic fibres). Each job held for more than 6 months was coded according to international and national classifications for occupations and industries.

The PNSM obtained the appropriate institutional review board authorisations. Written informed consent for participation in the study was obtained from all participants.

\section{Asbestos exposure assessment}

Asbestos exposure was assessed by retrospective expertise. ${ }^{8} 18$ Two experts (an industrial hygienist and an occupational physician) analysed each subject's questionnaire blinded to casecontrol status. ${ }^{19}$

For occupational exposure, each job held for at least 6 months by a subject was translated into four semiquantitative occupational asbestos exposure parameters, including the probability of exposure (possible, definite), frequency of exposure (sporadic, intermittent, frequent or continuous), intensity of exposure (low, medium, high, very high), and the route of exposure (direct, indirect). Table 1 describes these exposure parameters. A subject occupationally exposed to asbestos was defined as a subject who had held at least one job with a non-null probability of exposure. For each subject, the maximal probability of exposure, duration of exposure (years), age at first exposure (years), time since first exposure (years), year at first exposure and a cumulative exposure index (CEI, expressed in fiber/mL-years) were defined. The CEI was calculated by summing the products of probability, frequency, intensity and duration of exposure of each job held by a given subject. Since job occupational exposure parameters are semiquantitative, numerical values were assigned to each of them (table 1 ). These
Table 1 Description of the exposure parameters used to assess asbestos exposure at job level

\begin{tabular}{llc}
\hline $\begin{array}{l}\text { Asbestos exposure } \\
\text { parameters }\end{array}$ & Definition & $\begin{array}{c}\text { Numerical } \\
\text { values* }\end{array}$ \\
\hline $\begin{array}{l}\text { Probability of } \\
\text { exposure }\end{array}$ & $\begin{array}{l}\text { Degree of confidence that exposure really } \\
\text { occurred, expressed in percent (\%) }\end{array}$ \\
Not exposed & 0 & 0 \\
Possible & $>0-50$ & 0.5 \\
$\begin{array}{l}\text { Definite } \\
\text { Frequency of }\end{array}$ & $>50-100$ & 1 \\
exposure & Expressed in percent of work time (\%) & \\
Sporadic & $>0-5$ & 0.025 \\
Occasional & $>5-30$ & 0.25 \\
$\begin{array}{l}\text { Frequent or } \\
\text { continuous }\end{array}$ & $>30-100$ & 0.75 \\
Intensity of exposure & Expressed in f/mL & \\
Low & $>0-0.1$ & 0.1 \\
Medium & $>0.1-1$ & 10 \\
High & $>1-10$ & 100 \\
Very high & $>10$ & 10 \\
\hline * Numerical values assigned to each category in order to calculate cumulative \\
exposure index.
\end{tabular}

assigned values were the same as those defined in a previous mesothelioma French case-control study, ${ }^{8}$ where authors concluded that these values had the best ability to show a clear dose-response relationship.

Lifetime non-occupational asbestos exposure was also assessed by expertise using information reported by subjects on the use of asbestos-containing materials or performed tasks. The probability, frequency and intensity of exposure, and the route of exposure (domestic, para-occupational and environmental) were assigned to each subject. The definitions of probability, frequency and intensity of exposure were the same as for occupational exposure, except for intensity where the 'low' category was split into 'very low' and 'low'. Domestic exposure was defined by do-it-yourself activities that might have involved asbestos-containing products, for example, home improvements, and brake and clutch repairs. Para-occupational exposure was considered with regard to asbestos-contaminated clothes of relatives, partners and parents who had jobs well known to be associated with asbestos exposure, or with a high risk for pleural mesothelioma. For environmental exposure, only self-reported living near an industrial source of asbestos was considered. ${ }^{18}$

\section{Statistical analysis}

Analyses were performed separately for men and women. ORs and 99\% CIs were estimated for the occupational and non-occupational asbestos exposure parameters using conditional logistic regression models for matched sets. All continuous exposure variables were arbitrarily categorised: duration of exposure; 1-10/>10-20/>20 years; age at first exposure: $\leq 15 />15-20 />20$ years; time since first exposure: $>19-40 />40-50 />50$ years; year at first exposure: $>1960 /$ $>1960-1977 />1977 ; \quad$ CEI: $>0-0.1 />0.1-1 />1-10 />10$ 'f/mL-years'(table 4). All population-attributable risks (ARp) and 99\% CIs were calculated using the Mantel-Haenszel estimation. $^{20}$ The non-occupational asbestos exposure ARp was estimated among matched sets where cases and controls were not occupationally exposed to asbestos. Considering all asbestos exposure, the overall ARp was estimated using OR comparing 
subjects occupationally and/or non-occupationally exposed to those never exposed at all. Given the long latency period of pleural mesothelioma, exposures occurring less than 20 years before diagnosis were not taken into account. ${ }^{8}$ Although asbestos exposure was retrospectively assessed by two experts in the domain, this expertise was mainly based on subjects' selfreported tasks or asbestos-containing materials used. Thus, we conducted several sensitivity analyses by setting as not exposed: (1) subjects initially assessed as possibly exposed; (2) subjects initially assessed as exposed at a very low intensity; (3) subjects initially assessed as possibly exposed at a very low intensity; (4) subjects initially assessed as possibly exposed or exposed at a very low level intensity. We also performed additional analyses by setting the lag period at 0,10 and 30 years.

\section{RESULTS}

The study sample comprised 437 cases (362 men, 75 women) and 874 controls ( 724 men, 150 women). Table 2 presents the main subjects' characteristics. Cases were ascertained in average near 12 months after they had been identified, but they were interviewed before the certification of the diagnosis and, on average, 3 months after they had been recorded. The socioeconomic category differed between cases and controls: $59.4 \%$ of male cases were blue-collar workers versus $32.2 \%$ for controls. Among females, $41.1 \%$ of cases were clerical and related, workers versus $28.5 \%$ of controls.

Table 3 presents the 10 most frequent occupations and industries among males. There was a slight variation in the proportion of occupations held by male cases and controls. For some occupations, the occurrence of asbestos exposure within those occupations differed between cases and controls; that is, 90.7\% of cases who ever held an occupation as sheet-metal workers were exposed to asbestos within this occupation versus $77.8 \%$ of controls.

The relationship between pleural mesothelioma and occupational asbestos exposure is reported in table 4. Among men, ORs for pleural mesothelioma were significantly increased for all exposure parameters, and a dose-response relationship was observed for all of them. OR for men exposed at less than $0.1 \mathrm{f} / \mathrm{mL}$-years compared to those never exposed was $4.0(99 \%$ CI 1.9 to 8.3 ) vs 67.0 (99\% CI 25.6 to 175.1 ) in men exposed at more than $10 \mathrm{f} / \mathrm{mL}$-years. Among women, a significant association between occupational asbestos exposure and pleural mesothelioma was also observed, OR for women ever exposed compared to those never exposed was 12.0 (99\% CI 3.5 to 41.7). The estimated occupational asbestos exposure ARp was $83.1 \%$ (99\% CI $74.5 \%$ to $91.7 \%$ ) in men and $41.7 \%(95 \%$ CI $25.3 \%$ to $58.0 \%$ ) in women.

Table 5 presents the association between non-occupational asbestos exposure and pleural mesothelioma among subjects never occupationally exposed, that is, 9 matched sets among males ( 9 cases and 18 controls) and 36 matched sets among females (36 cases and 72 controls). OR for men ever nonoccupationally exposed to asbestos compared to those never exposed was 2.4 (99\% CI 0.2 to 26.7) and increased to 4.3 (99\% CI 1.2 to 15.1 ) for women. The non-occupational asbestos ARp for subjects never occupationally exposed was $20.0 \%$ (99\% CI $-33.5 \%$ to $73.5 \%$ ) in men and $38.7 \%$ (99\% CI $8.4 \%$ to $69.0 \%$ ) in women.

The ARp related to overall asbestos exposure (occupational and non-occupational) is presented in table 6 . The risk of pleural mesothelioma was strongly associated with asbestos exposure with a slight difference between men $(\mathrm{OR}=13.0(99 \%$ CI 6.2 to 27.5$)$ ) and women $(\mathrm{OR}=8.0(99 \% \mathrm{CI} 2.9$ to 21.8$)$ ).

Table 2 Main characteristics of subjects: 437 cases (362 men; 75 women) and 874 controls (724 men; 150 women), French case-control study, 1998-2002

\begin{tabular}{|c|c|c|c|c|c|c|c|c|}
\hline & \multicolumn{4}{|c|}{ Men (1 086) } & \multicolumn{4}{|c|}{ Women (225) } \\
\hline & \multicolumn{2}{|c|}{ Cases (362) } & \multicolumn{2}{|c|}{ Controls (724) } & \multicolumn{2}{|c|}{ Cases (75) } & \multicolumn{2}{|c|}{ Controls (150) } \\
\hline & n & $\%$ & $\mathrm{n}$ & $\%$ & n & $\%$ & $\mathrm{n}$ & $\%$ \\
\hline \multicolumn{9}{|l|}{ Age (years) } \\
\hline Mean (SD) & \multicolumn{2}{|c|}{$67.6(9.3)$} & \multicolumn{2}{|c|}{$66.8(9.1)$} & \multicolumn{2}{|c|}{$66.6(9.1)$} & \multicolumn{2}{|c|}{$65.8(8.9)$} \\
\hline Range & \multicolumn{2}{|c|}{$41-93$} & \multicolumn{2}{|c|}{$41-89$} & \multicolumn{2}{|c|}{$41-92$} & \multicolumn{2}{|c|}{$41-89$} \\
\hline \multicolumn{9}{|l|}{ Education level (years) } \\
\hline$\leq 14$ & 185 & 51.1 & 275 & 38.0 & 33 & 44.0 & 60 & 40.0 \\
\hline$>14$ & 177 & 48.9 & 449 & 62.0 & 42 & 56.0 & 90 & 60.0 \\
\hline \multicolumn{9}{|l|}{ Diagnostic-ascertainment period (months) } \\
\hline Mean (SD) & \multicolumn{4}{|c|}{$12.7(18.8)$} & \multicolumn{2}{|c|}{$12.1(15.2)$} & & \\
\hline Range & \multicolumn{4}{|c|}{$0-97.1$} & \multicolumn{2}{|c|}{$0.2-65.9$} & & \\
\hline \multicolumn{9}{|l|}{ Diagnostic-interview period (months) } \\
\hline Mean (SD) & \multicolumn{4}{|c|}{$3.4(3.9)$} & \multicolumn{4}{|c|}{$3.4(4.4)$} \\
\hline Range & \multicolumn{4}{|c|}{$0-43.7$} & \multicolumn{4}{|c|}{$0-36.3$} \\
\hline \multicolumn{9}{|l|}{ Last held occupation (ISCO 1968 major group)* } \\
\hline 0/1 Professional, technical and related workers & 49 & 13.5 & 146 & 20.2 & 5 & 6.9 & 31 & 21.5 \\
\hline 2 Administrative and managerial workers & 15 & 4.1 & 68 & 9.4 & 3 & 4.1 & 1 & 0.7 \\
\hline 3 Clerical and related workers & 34 & 9.4 & 91 & 12.6 & 30 & 41.1 & 41 & 28.5 \\
\hline 4 Sales workers & 23 & 6.4 & 69 & 9.5 & 7 & 9.6 & 13 & 9.0 \\
\hline 5 Service workers & 16 & 4.4 & 48 & 6.6 & 16 & 21.9 & 34 & 23.6 \\
\hline $\begin{array}{l}6 \text { Agricultural, animal husbandry and forestry } \\
\text { workers; fishermen; hunters }\end{array}$ & 10 & 2.8 & 69 & 9.5 & 3 & 4.1 & 4 & 2.8 \\
\hline $\begin{array}{l}\text { 7/8/9 Production and related workers, transport } \\
\text { equipment operators and labourers }\end{array}$ & 215 & 59.4 & 233 & 32.2 & 9 & 12.3 & 20 & 13.9 \\
\hline
\end{tabular}


Table 3 Occupational asbestos exposure: proportion of exposed men in the most represented occupations and industries, French case-control study, 1998-2002

\begin{tabular}{|c|c|c|c|c|c|c|c|c|}
\hline & \multicolumn{4}{|c|}{ Cases (362) } & \multicolumn{4}{|c|}{ Controls (724) } \\
\hline & \multirow{2}{*}{ n } & \multirow{2}{*}{$\%$} & \multicolumn{2}{|c|}{ Exposed within job } & \multirow{2}{*}{ n } & \multirow{2}{*}{$\%$} & \multicolumn{2}{|c|}{ Exposed within job } \\
\hline & & & $\mathbf{n}$ & $\%$ & & & n & $\%$ \\
\hline \multicolumn{9}{|l|}{ Occupations (ISCO Edition 1968) } \\
\hline 8-73 Sheet-metal workers & 54 & 14.9 & 49 & 90.7 & 27 & 3.7 & 21 & 77.8 \\
\hline 8-49 Machinery fitters, machine assemblers n.e.c. ${ }^{*}$ & 46 & 12.7 & 31 & 67.4 & 37 & 5.1 & 25 & 67.6 \\
\hline 7-00 Production supervisors and general foremen & 44 & 12.2 & 31 & 70.5 & 56 & 7.7 & 40 & 71.4 \\
\hline 8-71 Plumbers and pipe fitters & 39 & 10.8 & 36 & 92.3 & 14 & 1.9 & 12 & 85.7 \\
\hline 8-41 Machinery fitters and machine assemblers & 37 & 10.2 & 21 & 56.8 & 30 & 4.1 & 13 & 43.3 \\
\hline 9-99 Labourers n.e.c.* & 36 & 9.9 & 24 & 66.7 & 27 & 3.7 & 15 & 55.6 \\
\hline 6-21 General farm workers & 31 & 8.6 & 0 & 0.0 & 86 & 11.9 & 4 & 4.7 \\
\hline 9-51 Bricklayers, stonemasons and tile setters & 29 & 8.0 & 25 & 86.2 & 31 & 4.3 & 26 & 83.9 \\
\hline 8-34 Machine-tool operators & 26 & 7.2 & 14 & 53.8 & 29 & 4.0 & 7 & 24.1 \\
\hline 9-54 Carpenters, joiners and parquetry workers & 26 & 7.2 & 21 & 80.8 & 27 & 3.7 & 20 & 74.1 \\
\hline \multicolumn{9}{|l|}{ Industries (ISIC Revision 2) } \\
\hline 5000 Construction & 129 & 35.6 & 109 & 84.5 & 140 & 19.3 & 105 & 75.0 \\
\hline 3841 Ship building and repairing & 65 & 18.0 & 58 & 89.2 & 20 & 2.8 & 19 & 95.0 \\
\hline 3813 Manufacture of structural metal products & 52 & 14.4 & 43 & 82.7 & 30 & 4.1 & 20 & 66.7 \\
\hline 1110 Agriculture and livestock production & 48 & 13.3 & 5 & 10.4 & 145 & 20.0 & 32 & 22.1 \\
\hline 6200 Retail trade & 33 & 9.1 & 8 & 24.2 & 94 & 13.0 & 19 & 20.2 \\
\hline 6100 Wholesale trade & 29 & 8.0 & 9 & 31.0 & 74 & 10.2 & 13 & 17.6 \\
\hline $\begin{array}{l}3819 \text { Manufacture of fabricated metal products } \\
\text { except machinery and equipment n.e.c. }{ }^{*}\end{array}$ & 24 & 6.6 & 13 & 54.2 & 24 & 3.3 & 6 & 25.0 \\
\hline 9100 Public administration & 24 & 6.6 & 6 & 25.0 & 71 & 9.8 & 11 & 15.5 \\
\hline 3845 Manufacture of aircraft & 23 & 6.4 & 10 & 43.5 & 27 & 3.7 & 10 & 37.0 \\
\hline 9310 Education services & 23 & 6.4 & 9 & 39.1 & 82 & 11.3 & 19 & 23.2 \\
\hline
\end{tabular}

The overall asbestos exposure ARp was $87.3 \%$ (99\% CI $78.9 \%$ to $95.7 \%)$ in men and $64.8 \%$ (99\% CI $45.4 \%$ to $84.3 \%)$ in women.

From the sensitivity analysis, in men, the overall ARp was $68.6 \%$ (99\% CI 58.0 to 79.1 ), $85.9 \%$ (99\% CI 77.2 to 94.7 ), $86.0 \%$ (99\% CI 77.2 to 94.7 ) and $68.6 \%$ (99\% CI 58.0 to 79.1) for analyses $1,2,3$ and 4, respectively. In women, the overall ARp was 26.7\% (99\% CI 12.0 to 41.3 ), 47.4\% (99\% CI 30.0 to 65.0 ), $52.0 \%$ (99\% CI 34.1 to 69.8 ) and $22.0 \%(99 \%$ CI 8.0 to 36.0 ) for analyses $1,2,3$ and 4, respectively (see online supplementary material).

\section{DISCUSSION}

This study permits to quantify the role of some aspects of nonoccupational asbestos exposure in the occurrence of pleural mesothelioma. When taking into account all kinds of asbestos exposure, $87.3 \%$ of male cases and $64.8 \%$ of female cases were attributable to asbestos.

In table 3, we observed an intravariability of asbestos exposure within each occupation and industry category. This is due to the exposure assessment method that incorporated experts' knowledge about that occupation or industry, as well as specific tasks performed, and circumstances of asbestos exposure reported by the subject himself.

The relationship between occupational asbestos exposure and occurrence of pleural mesothelioma is now well known. To date, several case-control studies have analysed this relationship, and all confirmed the causal link between occupational asbestos exposure and pleural mesothelioma, ${ }^{4} 7-1321$ but few have estimated the population-attributable risk of asbestos exposure for pleural mesothelioma. ${ }^{4} 51013$ Results from the present study are consistent with the literature. However, they may not be generalisable to countries, such as developing countries, countries with different pattern of industrialisation, or which used different type of asbestos fibres.

In France, almost all the asbestos used was imported, and chrysotile seems to have been the most common used type. Sources of asbestos exposure came from mainly construction industry, shipbuilding and repairing industry, manufacture of asbestos cement products, metal-working industry and motor vehicles manufacture or repairing. ${ }^{8}$

Our results support the role of non-occupational asbestos exposure in the aetiology of pleural mesothelioma and make it possible to quantify the weight of such exposure in the occurrence of pleural mesothelioma, especially among women. There is now stronger evidence that pleural mesothelioma may be induced by non-occupational exposure. Several populationbased case-control studies have established an association between para-occupational exposure and the occurrence of pleural mesothelioma, ${ }^{22-24}$ as well as for household exposure. $^{7}$ A meta-analysis of eight studies provided a summary relative risk of 8.1 (95\% CI 5.3 to 12.0$).{ }^{26}$ While there is evidence of an association between asbestos exposure from a geological source and the increased incidence of pleural mesothelioma, ${ }^{27}$ recent studies have shown an increased risk of pleural mesothelioma associated with environmental exposure related to proximity with an asbestos plant, ${ }^{28} 29$ as well as environmental exposure due to residence near asbestos mines. ${ }^{11} 30$ Bourdes et al reported a summary relative risk for environmental exposure due either to asbestos mines or an asbestos 
Table 4 Occupational asbestos exposure and risk of pleural mesothelioma, 437 cases (362 men; 75 women) and 874 controls (724 men; 150 women), French case-control study, $1998-2002$

\begin{tabular}{|c|c|c|c|c|c|c|c|c|c|c|c|c|c|c|}
\hline \multirow[b]{3}{*}{ Occupational asbestos exposure } & & \multicolumn{6}{|c|}{ Men (1 086) } & & \multicolumn{6}{|c|}{ Women (225) } \\
\hline & & \multicolumn{2}{|c|}{ Cases (362) } & \multicolumn{2}{|c|}{ Controls (724) } & \multirow[b]{2}{*}{ OR } & \multirow[b]{2}{*}{$99 \% \mathrm{Cl}$} & & \multicolumn{2}{|c|}{ Cases (75) } & \multicolumn{2}{|c|}{ Controls (150) } & \multirow[b]{2}{*}{ OR } & \multirow[b]{2}{*}{$99 \% \mathrm{Cl}$} \\
\hline & & $\mathrm{n}$ & $\%$ & $\mathrm{n}$ & $\%$ & & & & $\mathrm{n}$ & $\%$ & $\mathrm{n}$ & $\%$ & & \\
\hline Not exposed & & 28 & 7.7 & 327 & 45.2 & 1.0 & - & & 41 & 54.7 & 139 & 92.7 & 1.0 & - \\
\hline Exposed & & 334 & 92.3 & 397 & 54.8 & 11.4 & 6.1 to 21.4 & & 34 & 45.3 & 11 & 7.3 & 12.0 & 3.5 to 41.7 \\
\hline Highest probability of exposure & $\begin{array}{l}\text { Possible } \\
\text { Definite }\end{array}$ & $\begin{array}{r}43 \\
291\end{array}$ & $\begin{array}{l}11.9 \\
80.4\end{array}$ & $\begin{array}{l}102 \\
295\end{array}$ & $\begin{array}{l}14.1 \\
40.7\end{array}$ & $\begin{array}{r}5.6 \\
13.2\end{array}$ & $\begin{array}{l}2.6 \text { to } 12.1 \\
7.0 \text { to } 25.0\end{array}$ & $\begin{array}{l}\text { Possible } \\
\text { Definite }\end{array}$ & $\begin{array}{l}19 \\
15\end{array}$ & $\begin{array}{l}25.3 \\
20.0\end{array}$ & $\begin{array}{l}8 \\
3\end{array}$ & $\begin{array}{l}5.3 \\
2.0\end{array}$ & $\begin{array}{r}9.6 \\
18.2\end{array}$ & $\begin{array}{l}2.4 \text { to } 38.1 \\
2.9 \text { to } 112.9\end{array}$ \\
\hline Duration of exposure (years) & $\begin{array}{l}1-10 \\
>10-20 \\
>20\end{array}$ & $\begin{array}{r}71 \\
78 \\
185\end{array}$ & $\begin{array}{l}19.6 \\
21.6 \\
51.1\end{array}$ & $\begin{array}{r}119 \\
95 \\
183\end{array}$ & $\begin{array}{l}16.4 \\
13.1 \\
25.3\end{array}$ & $\begin{array}{r}7.9 \\
11.2 \\
13.9\end{array}$ & $\begin{array}{l}3.8 \text { to } 16.1 \\
5.4 \text { to } 23.3 \\
7.2 \text { to } 27.0\end{array}$ & $\begin{array}{l}1-10 \\
>10\end{array}$ & $\begin{array}{l}19 \\
15\end{array}$ & $\begin{array}{l}25.3 \\
20.0\end{array}$ & $\begin{array}{l}4 \\
7\end{array}$ & $\begin{array}{l}2.7 \\
4.6\end{array}$ & $\begin{array}{r}36.2 \\
6.6\end{array}$ & $\begin{array}{l}2.6 \text { to } 513.3 \\
1.6 \text { to } 27.8\end{array}$ \\
\hline Age at first exposure (years) & $\begin{array}{l}\leq 15 \\
>15-20 \\
>20\end{array}$ & $\begin{array}{r}77 \\
122 \\
135\end{array}$ & $\begin{array}{l}21.3 \\
33.7 \\
37.3\end{array}$ & $\begin{array}{r}63 \\
115 \\
219\end{array}$ & $\begin{array}{r}8.7 \\
15.9 \\
30.2\end{array}$ & $\begin{array}{r}15.8 \\
14.6 \\
8.5\end{array}$ & $\begin{array}{l}7.4 \text { to } 33.8 \\
7.3 \text { to } 29.4 \\
4.4 \text { to } 16.4\end{array}$ & $\begin{array}{l}\leq 20 \\
>20\end{array}$ & $\begin{array}{l}14 \\
20\end{array}$ & $\begin{array}{l}18.7 \\
26.6\end{array}$ & $\begin{array}{l}2 \\
9\end{array}$ & $\begin{array}{l}1.3 \\
6.0\end{array}$ & $\begin{array}{r}38.2 \\
8.3\end{array}$ & $\begin{array}{l}2.4 \text { to } 601.3 \\
2.2 \text { to } 31.5\end{array}$ \\
\hline Time since first exposure (years) & $\begin{array}{l}>19-40 \\
>40-50 \\
>50\end{array}$ & $\begin{array}{r}81 \\
114 \\
139\end{array}$ & $\begin{array}{l}22.4 \\
31.5 \\
38.4\end{array}$ & $\begin{array}{l}119 \\
131 \\
147\end{array}$ & $\begin{array}{l}16.4 \\
18.1 \\
20.3\end{array}$ & $\begin{array}{r}8.3 \\
12.6 \\
13.4\end{array}$ & $\begin{array}{l}4.0 \text { to } 17.2 \\
6.2 \text { to } 25.6 \\
6.7 \text { to } 26.8\end{array}$ & $\begin{array}{l}>19-40 \\
>40\end{array}$ & $\begin{array}{l}15 \\
19\end{array}$ & $\begin{array}{l}20.0 \\
25.3\end{array}$ & $\begin{array}{l}5 \\
6\end{array}$ & $\begin{array}{l}3.3 \\
4.0\end{array}$ & $\begin{array}{l}10.2 \\
14.2\end{array}$ & $\begin{array}{l}2.0 \text { to } 50.5 \\
2.7 \text { to } 75.0\end{array}$ \\
\hline Year at first exposure & $\begin{array}{l}\leq 1960 \\
>1960-1977 \\
>1977\end{array}$ & $\begin{array}{r}256 \\
75 \\
3\end{array}$ & $\begin{array}{r}70.7 \\
20.7 \\
0.9\end{array}$ & $\begin{array}{r}275 \\
108 \\
14\end{array}$ & $\begin{array}{r}38.0 \\
14.9 \\
1.9\end{array}$ & $\begin{array}{r}13.8 \\
8.4 \\
1.9\end{array}$ & $\begin{array}{l}7.2 \text { to } 26.7 \\
4.0 \text { to } 17.6 \\
0.3 \text { to } 11.8\end{array}$ & $\begin{array}{l}\leq 1960 \\
>1960-1977 \\
>1977\end{array}$ & $\begin{array}{r}19 \\
13 \\
2\end{array}$ & $\begin{array}{r}25.3 \\
17.3 \\
2.7\end{array}$ & $\begin{array}{l}6 \\
4 \\
1\end{array}$ & $\begin{array}{l}4.0 \\
2.7 \\
0.6\end{array}$ & $\begin{array}{r}14.3 \\
10.6 \\
7.9\end{array}$ & $\begin{array}{l}2.7 \text { to } 75.8 \\
2.1 \text { to } 55.9 \\
0.2 \text { to } 258.8\end{array}$ \\
\hline Cumulative exposure (« f/mL-years ») & $\begin{array}{l}>0-0.1 \\
>0.1-1 \\
>1-10 \\
>10\end{array}$ & $\begin{array}{r}54 \\
68 \\
115 \\
97\end{array}$ & $\begin{array}{l}14.9 \\
18.8 \\
31.8 \\
26.8\end{array}$ & $\begin{array}{r}181 \\
121 \\
68 \\
27\end{array}$ & $\begin{array}{r}25.0 \\
16.7 \\
9.4 \\
3.7\end{array}$ & $\begin{array}{r}4.0 \\
8.3 \\
22.5 \\
67.0\end{array}$ & $\begin{array}{c}1.9 \text { to } 8.3 \\
3.8 \text { to } 17.7 \\
10.4 \text { to } 48.7 \\
25.6 \text { to } 175.1\end{array}$ & $\begin{array}{l}>0 \text { to } 0.1 \\
>0.1\end{array}$ & $\begin{array}{l}13 \\
21\end{array}$ & $\begin{array}{l}17.3 \\
28.0\end{array}$ & $\begin{array}{l}6 \\
5\end{array}$ & $\begin{array}{l}4.0 \\
3.3\end{array}$ & $\begin{array}{r}6.9 \\
23.7\end{array}$ & $\begin{array}{l}1.5 \text { to } 30.9 \\
3.3 \text { to } 168.53\end{array}$ \\
\hline Attributable risk $(99 \% \mathrm{Cl})(\%)$ & & & & & & 83.1 & to 91.7 ) & & & & & & 41.7 & to 58.0$)$ \\
\hline
\end{tabular}


Table 5 Non occupational asbestos exposure and risk of pleural mesothelioma among subjects non-exposed to occupational asbestos exposure, 45 cases (9 men; 36 women) and 90 controls (18 men; 72 women), French case-control study, 1998-2002

\begin{tabular}{|c|c|c|c|c|c|c|c|c|c|c|c|c|}
\hline \multirow{3}{*}{$\begin{array}{l}\text { Non-occupational } \\
\text { asbestos exposure }\end{array}$} & \multicolumn{6}{|c|}{ Men } & \multicolumn{6}{|c|}{ Women } \\
\hline & \multicolumn{2}{|c|}{ Cases (9) } & \multicolumn{2}{|c|}{ Controls (18) } & \multirow[b]{2}{*}{ OR } & \multirow[b]{2}{*}{$99 \% \mathrm{Cl}$} & \multicolumn{2}{|c|}{ Cases (36) } & \multicolumn{2}{|c|}{ Controls (72) } & \multirow[b]{2}{*}{ OR } & \multirow[b]{2}{*}{$99 \% \mathrm{Cl}$} \\
\hline & $\mathrm{n}$ & $\%$ & $\mathbf{n}$ & $\%$ & & & $\mathbf{n}$ & $\%$ & $\mathrm{n}$ & $\%$ & & \\
\hline Not exposed & 6 & 66.7 & 15 & 83.3 & 1.0 & - & 17 & 47.2 & 56 & 77.8 & 1.0 & - \\
\hline Exposed & 3 & 33.3 & 3 & 16.7 & 2.4 & 0.2 to 26.7 & 19 & 52.8 & 16 & 22.2 & 4.3 & 1.2 to 15.1 \\
\hline \multicolumn{13}{|l|}{$\begin{array}{l}\text { Highest probability } \\
\text { of exposure }\end{array}$} \\
\hline Possible & 0 & 0.0 & 1 & 5.6 & - & - & 11 & 30.6 & 13 & 18.1 & 3.2 & 0.8 to 13.2 \\
\hline Definite & 3 & 33.3 & 2 & 11.1 & 4.6 & 0.2 to 96.9 & 8 & 22.2 & 3 & 4.1 & 7.5 & 1.2 to 48.0 \\
\hline $\begin{array}{l}\text { Attributable risk } \\
(99 \% \mathrm{Cl})(\%)\end{array}$ & & & & & \multicolumn{4}{|c|}{$20.0(-33.5$ to 73.5$)$} & & & \multicolumn{2}{|c|}{38.7 (8.4 to 69.0$)$} \\
\hline
\end{tabular}

processing plant of 7.0 (95\% CI 4.7 to 11.0$)$. To date, there is only weak evidence of a possible effect of passive exposure in buildings containing asbestos on the occurrence of pleural mesothelioma. ${ }^{15}$

As in most case-control studies, the major limitation of this study is the retrospective assessment of exposure. While we are confident about the reliability of the occupational and paraoccupational asbestos exposure assessment, this is not the case for domestic and environmental asbestos exposure. In the questionnaire, there were specific questions about domestic use of asbestos, or the proximity to an asbestos-processing plant. The reliability of such assessment is poor and is highly subject to recall bias. ${ }^{31}$ Besides the proximity to an asbestos-processing plant, we did not consider other potential sources of environmental exposure, such as residence in buildings containing asbestos, or proximity to construction sites involving asbestos. Moreover, since we did not assess environmental exposure through lifetime residential distance from an asbestos-processing plant or other industrial sources but through self-report, we may have underestimated this kind of exposure, thereby leading to an underestimation of non-occupational and overall ARp. This hypothesis could explain the observed difference in ARp between men and women. Indeed, since $92 \%$ of male cases and only $45 \%$ of female cases were occupationally exposed, the ARp among women should be more affected by the bias induced by the underestimation of environmental exposure than that among men. A recent French study on the spatial distributions of male and female incidence of mesothelioma cases with and without any identified occupational or nonoccupational asbestos exposure suggested the major influence of asbestos in female mesothelioma, likely through unknown environmental exposure. ${ }^{32}$ However, we cannot exclude a possible overestimation of the non-occupational ARp and, thus, the overall ARp due to recall bias if we hypothesise that controls tended to under-report environmental or domestic exposure compared to cases. This effect might have been more extreme among women, since most cases were not occupationally exposed leading to a possible over-reporting of environmental or domestic exposure. This plausible hypothesis may also explain the observed difference between men and women for the non-occupational ARp. Indeed, from the sensitivity analyses conducted which aimed to assess the extent of this recall bias, the overall ARp varied from $68.6 \%$ to $87.3 \%$ among men, and from $22.0 \%$ to $64.8 \%$ among women. Only $11.6 \%$ of male cases were assessed as possibly exposed and $0.6 \%$ at a very low intensity versus $42.7 \%$ and $28.6 \%$ of female cases, respectively. Female cases were mainly considered as exposed at a very low intensity through domestic exposure, that is, use of baking trays, cooking gloves, toasters and ironing boards. Results from these sensitivity analyses demonstrate the difficulty of estimating precisely the overall asbestos ARp among women. Indeed, since the ARp among men is mostly driven by occupational exposure, and because the assessment of such exposure relies on the knowledge of experts in industrial hygiene, there is little impact

Table 6 All asbestos exposure and risk of pleural mesothelioma, 437 cases ( 362 men; 75 women) and 874 controls (724 men; 150 women), French case-control study, 1998-2002

\begin{tabular}{|c|c|c|c|c|c|c|c|c|c|c|c|c|}
\hline \multirow[b]{3}{*}{ All asbestos exposure } & \multicolumn{6}{|c|}{ Men (1 086) } & \multicolumn{6}{|c|}{ Women (225) } \\
\hline & \multicolumn{2}{|c|}{ Cases (362) } & \multicolumn{2}{|c|}{ Controls (724) } & \multirow[b]{2}{*}{ OR } & \multirow[b]{2}{*}{$99 \% \mathrm{Cl}$} & \multicolumn{2}{|c|}{ Cases (75) } & \multicolumn{2}{|c|}{ Controls (150) } & \multirow[b]{2}{*}{ OR } & \multirow[b]{2}{*}{$99 \% \mathrm{Cl}$} \\
\hline & n & $\%$ & $\mathrm{n}$ & $\%$ & & & $\mathbf{n}$ & $\%$ & n & $\%$ & & \\
\hline Not exposed & 17 & 4.7 & 263 & 36.3 & 1.0 & - & 19 & 25.3 & 104 & 69.3 & 1.0 & - \\
\hline Exposed & 345 & 95.3 & 461 & 63.7 & 13.0 & 6.2 to 27.5 & 56 & 74.7 & 46 & 30.7 & 8.0 & 2.9 to 21.8 \\
\hline Occupational only & 264 & 76.5 & 317 & 68.7 & & & 26 & 46.4 & 9 & 19.6 & & \\
\hline Non occupational only & 11 & 3.2 & 64 & 13.9 & & & 22 & 39.3 & 35 & 76.1 & & \\
\hline Occupational and non-occupational & 70 & 20.3 & 80 & 17.4 & & & 8 & 14.3 & 2 & 4.3 & & \\
\hline \multicolumn{13}{|l|}{ Highest probability of exposure } \\
\hline Possible & 42 & 11.6 & 104 & 14.4 & 6.8 & 2.8 to 16.2 & 32 & 42.7 & 38 & 25.3 & 5.8 & 2.0 to 17.0 \\
\hline Probable & 303 & 83.7 & 357 & 49.3 & 14.8 & 7.0 to 31.6 & 24 & 32.0 & 8 & 5.4 & 14.7 & 4.0 to 54.2 \\
\hline Attributable risk (99\% Cl) (\%) & & & & & \multicolumn{2}{|c|}{87.3 (78.9 to 95.7$)$} & & & & & \multicolumn{2}{|c|}{64.8 (45.4 to 84.3$)$} \\
\hline
\end{tabular}


of the sensitivity of the 'ever exposed' definition on the ARp estimation. However, since only $40 \%$ of female cases are attributable to occupational asbestos exposure, the overall ARp in women is driven by occupational and non-occupational asbestos exposure. Thus, among women, the 'ever exposed' definition, and especially, the 'non-occupationally ever exposed' definition, has an important impact on the estimation of ARp.

The PNSM relies on the exhaustive recording of all incident primary pleural tumours in representative districts of France. ${ }^{17}$ Only incident cases who were alive at the time of the interview were included in these analyses. From a substudy on nonresponse bias, it appeared that the sociodemographic characteristics of cases who died before interview or refused to answer questions, did not differ from those of the cases included in this study. ${ }^{18}$ Cases who had died before the interview seemed to be less occupationally exposed than those included (among males, $80.3 \%$ vs $92.3 \%$, respectively; among women, $18.7 \%$ vs $45.3 \%$, respectively). However, occupational asbestos exposure was derived from simplified questionnaires and mainly assessed through job titles. According to controls selection, it appeared that there were more blue-collar workers among refusing controls and more white-collar workers among participating controls, leading to a possible underestimation of occupational asbestos exposure among our control population. ${ }^{33}$

As in all previous published population-based mesothelioma case-control studies, the prevalence of blue collar workers was higher among cases than among controls. We did not adjust for this difference in socioeconomic status between cases and controls, since this is a variable that is linked to asbestos exposure but cannot be considered as potential causal factor of pleural mesothelioma. ${ }^{34}$

The definition of a lag period of 20 years had no impact on results since they were similar when we implemented a lag period strategy of 0,10 and 30 years (see online supplementary material).

Since we have performed several comparisons, we have decided to present results with 99\% CIs instead of the traditional 95\% CIs. In order to estimate the 99\% CIs for ARp, we used a method proposed by Greenland, ${ }^{20}$ which is based on the Mantel-Haenszel estimation and is consistent for sparse data as found in individually matched studies. Since it exists several variance formulas in the literature, we also derived 99\% CIs using the bootstrap method, ${ }^{35}$ and results were very similar (see online supplementary material).

\section{CONCLUSION}

After quantification of the role of non-occupational asbestos exposure in the occurrence of pleural mesothelioma, approximately $35 \%$ of female cases were still not attributable to asbestos exposure. Since domestic and environmental exposures are hardly identifiable, the overall ARp could be underestimated owing to the underestimation of non-occupational asbestos exposure. Explanations, such as other factors involved in the aetiology of pleural mesothelioma, are also possible.

\footnotetext{
Author affiliations

${ }^{1}$ Univ. Bordeaux, ISPED, Centre INSERM U897-Epidemiologie-Biostatistique Equipe sante environnement, Bordeaux, France

${ }^{2}$ INSERM, ISPED, Centre INSERM U897-Epidemiologie-Biostatistique, Equipe sante environnement, Bordeaux, France

${ }^{3}$ Departement Sante Travail, Institut de Veille Sanitaire, Equipe Associee en Sante Travail, Bordeaux, France

${ }^{4}$ Registre Multicentrique a Vocation Nationale des Mesotheliomes Pleuraux

(MESONAT), Hopital de la Cote de Nacre, Caen, France
}

${ }^{5}$ Service d'Oncologie Thoracique, Maladie de la Plèvre et Pneumologie Interventionnelle, Hopital Nord, Aix-Marseille Universite, Marseille, France ${ }^{6}$ Institut Interuniversitaire de Medecine du Travail de Paris Ile de France, Créteil, France

${ }^{7}$ Departement Sante Travail, Institut de Veille Sanitaire, Saint Maurice, France ${ }^{8}$ Service d Anatomie Pathologique, Hopital de la Cote de Nacre, Caen, France ${ }^{9}$ Faculte de Medecine, INSERM U955, Universite Paris-Est Creteil, Creteil, France

Acknowledgements PNSM Scientific Committee (1998-2002): P Boffetta (Chairman), E Chailleux, J Esteve, J Faivre, and D Hemon. PNSM Study Group: Steering Committee: MG (Scientific Coordinator, PNSM), AGSI (Operational Coordinator, PNSM), El (Head, PNSM), PR (Head, Pilot Center), SD (Pilot Center), FG-S (Head, pathology Center; Head, MESONAT Registry), N Le Stang (MESONAT Registry), PA (Head, Clinical Center), C Frenay (Clinical Center), PB (Head, Etiology Center), CG (Etiology Center), M Saves (Etiology Center), JCP (Head, Social Medical Center), and SC's (Social Medical Center). National MESONAT Registry for Pleural Mesothelioma: FG-S (Coordinator), N Le Stang, A de Quillacq, AGSI, PR, and SD; Registries managers: P Arveux, A Buemi, PA, PB, M Colonna, P Czernichow, A Danzon, J Faivre, B Lapotre-Ledoux, M F Le Bodic, M Letourneux, P Malfait, F Menegoz, F Molinie, N Raverdy, and M Velten; Investigators: S Amosse, S Audignon, K Astruc, A M Aude, P Benattar, G Blaizot, H Berron, C Berthaut, $\checkmark$ Bouvier, L Calatayud, S Chamming's, A M Chouillet, C Cotte, C Dantas, M L De Abreu, P Delafosse, F Demesmay, C Dufour, S Elia, M Grandadam, C Halby, A Jaffre, K Khairi, P Louvat, C Madeline, M L Marty, D Provost, V Queuche, M Ramadour, S Schwall, M Sousbie, P Dufour, A D Tagri, P Vialard, B Wurtz, A Yacine, and M Zazzo. National MESOPATH Network of Mesothelioma Pathologists: F G-S (Coordinator), I Abd Alsamad, H Begueret, E Brambilla, F Capron, MC Copin, A Fondimare, A Foulet-Roge, L Garbe, B Gosselin, O Groussard, L Guillou, A Y de Lajartre, F Lange, R Loire, M Nebut, JM Piquenot, F Thivolet-Bejui, B Vergier, and JM Vignaud. E Mouillet for her bibliographic support; R Cooke for his careful reading of the manuscript; the patients and their next of kin, the physicians and the pathologists who made this study possible.

Contributors AL: supervision of analysis and manuscript writing. CG: conduct analysis and data monitoring. SD: involved in exposure assessment and data monitoring. SA: involved in exposure assessment. PR: coordinator involved in study design, exposure assessment, data management, statistical analysis, and manuscript development. PB: overall supervision of all aspects of this manuscript, including study design, exposure assessment, analytical approach, choice of exposure parameters and interpretation of the findings. Other co-authors: responsible for original data collection and/or for the decisions taken about exposure assessment and analysis strategy, as well as review of the manuscript.

Funding National Institute for Public Health Surveillance (InVS), the Ministries of Labor and Health, and the Foundation for Medical Research.

Competing interests None.

Ethics approval Commission nationale de l'informatique et des libertés (CNIL).

Provenance and peer review Not commissioned; externally peer reviewed.

Data sharing statement All sensitivity analyses are available from the corresponding author upon request (email address: aude.lacourt@isped. u-bordeaux2.fr).

\section{REFERENCES}

1 Dikensoy 0 . Mesothelioma due to environmental exposure to erionite in Turkey. Curr Opin Pulm Med 2008;14:322-5.

2 Wagner JC, Sleggs CA, Marchand P. Diffuse pleural mesothelioma and asbestos exposure in the North Western Cape Province. Br J Ind Med 1960;17:260-71.

3 Tossavainen A. Global use of asbestos and the incidence of mesothelioma. Int J Occup Environ Health 2004;10:22-5.

4 Agudo A, Gonzalez CA, Bleda MJ, et al. Occupation and risk of malignant pleural mesothelioma: A case-control study in Spain. Am J Ind Med 2000;37:159-68.

5 Aguilar-Madrid G, Robles-Perez E, Juarez-Perez CA, et al. Case-control study of pleural mesothelioma in workers with social security in Mexico. Am J Ind Med 2010:53:241-51

6 Hodgson JT, Darnton A. The quantitative risks of mesothelioma and lung cancer in relation to asbestos exposure. Ann Occup Hyg 2000;44:565-601.

7 Howel D, Arblaster L, Swinburne L, et al. Routes of asbestos exposure and the development of mesothelioma in an English region. Occup Environ Med 1997;54:403-9

8 Iwatsubo Y, Pairon JC, Boutin C, et al. Pleural mesothelioma: dose-response relation at low levels of asbestos exposure in a French population-based case-control study. Am J Epidemiol 1998;148:133-42.

9 Pintos J, Parent ME, Case BW, et al. Risk of mesothelioma and occupational exposure to asbestos and man-made vitreous fibers: evidence from two case-control studies in Montreal, Canada. J Occup Environ Med 2009:51:1177-84. 
10 Rake C, Gilham C, Hatch J, et al. Occupational, domestic and environmental mesothelioma risks in the British population: a case-control study. $\mathrm{Br} J$ Cancer 2009; 100:1175-83.

11 Rees D, Goodman K, Fourie E, et al. Asbestos exposure and mesothelioma in South Africa. S Afr Med J 1999:89:627-34.

12 Rodelsperger $\mathrm{K}$, Jockel $\mathrm{KH}$, Pohlabeln $\mathrm{H}$, et al. Asbestos and man-made vitreous fibers as risk factors for diffuse malignant mesothelioma: results from a German hospital-based case-control study. Am J Ind Med 2001;39:262-75.

13 Spirtas R, Heineman EF, Bernstein L, et al. Malignant mesothelioma: attributable risk of asbestos exposure. Occup Environ Med 1994;51:804-11.

14 Ferrante D, Bertolotti M, Todesco A, et al. Cancer mortality and incidence of mesothelioma in a cohort of wives of asbestos workers in Casale Monferrato, Italy. Environ Health Perspect 2007;115:1401-5.

15 Goldberg M, Luce D. The health impact of nonoccupational exposure to asbestos: what do we know? Eur J Cancer Prev 2009;18:489-503.

16 Magnani C, Dalmasso P, Biggeri A, et al. Increased risk of malignant mesothelioma of the pleura after residential or domestic exposure to asbestos: a case-control study in Casale Monferrato, Italy. Environ Health Perspect 2001;109:915-19.

17 Goldberg $M$, Imbernon E, Rolland $P$, et al. The French National Mesothelioma Surveillance Program. Occup Environ Med 2006;63:390-5.

18 Rolland P, Gramond C, Lacourt A, et al. Occupations and industries in France at high risk for pleural mesothelioma: A population-based case-control study (1998-2002). Am J Ind Med 2010;53:1207-19.

19 Gramond C, Rolland P, Lacourt A, et al. Choice of rating method for assessing occupational asbestos exposure: study for compensation purposes in France. Am J Ind Med 2012;55:440-9.

20 Greenland S. Variance estimators for attributable fraction estimates consistent in both large strata and sparse data. Stat Med 1987;6:701-8.

21 Cicioni C, London SJ, Garabrant DH, et al. Occupational asbestos exposure and mesothelioma risk in Los Angeles County: application of an occupational hazard survey job-exposure matrix. Am J Ind Med 1991;20:371-9.

22 McDonald AD, McDonald JC. Malignant mesothelioma in North America. Cancer 1980;46:1650-6.

23 Newhouse ML, Thompson H. Mesothelioma of pleura and peritoneum following exposure to asbestos in the London area. Br J Ind Med 1965;22:261-9.
24 Vianna NJ, Polan AK. Non-occupational exposure to asbestos and malignant mesothelioma in females. Lancet 1978;1:1061-3.

25 Magnani C, Agudo A, Gonzalez CA, et al. Multicentric study on malignant pleural mesothelioma and non-occupational exposure to asbestos. Br J Cancer 2000;83:104-11.

26 Bourdes V, Boffetta P, Pisani P. Environmental exposure to asbestos and risk of pleural mesothelioma: review and meta-analysis. Eur J Epidemiol 2000;16: 411-17.

27 Constantopoulos SH. Environmental mesothelioma associated with tremolite asbestos: lessons from the experiences of Turkey, Greece, Corsica, New Caledonia and Cyprus. Regul Toxicol Pharmacol 2008;52:S110-15.

28 Maule MM, Magnani C, Dalmasso P, et al. Modeling mesothelioma risk associated with environmental asbestos exposure. Environ Health Perspect 2007;115: 1066-71.

29 Musti M, Pollice A, Cavone D, et al. The relationship between malignant mesothelioma and an asbestos cement plant environmental risk: a spatial case-control study in the city of Bari (Italy). Int Arch Occup Environ Health 2009:82:489-97.

30 Kielkowski D, Nelson G, Rees D. Risk of mesothelioma from exposure to crocidolite asbestos: a 1995 update of a South African mortality study. Occup Environ Med 2000;57:563-7.

31 Rothman KJ, Greenland S, Lash TL. Modern epidemiology. Third edn. Philadelphia: Lippincott Williams \& Wilkins, 2008.

32 Goldberg S, Rey G, Luce D, et al. Possible effect of environmental exposure to asbestos on geographical variation in mesothelioma rates. Occup Environ Med 2010;67:417-21.

33 Lacourt A, Rolland P, Gramond C, et al. Attributable risk in men in two French case-control studies on mesothelioma and asbestos. Eur J Epidemiol 2010;25:799-806.

34 Richiardi L, Barone-Adesi F, Merletti F, et al. Using directed acyclic graphs to consider adjustment for socioeconomic status in occupational cancer studies. J Epidemiol Community Health 2008;62:e14.

35 Llorca J, Delgado-Rodriguez M. A comparison of several procedures to estimate the confidence interval for attributable risk in case-control studies. Stat Med 2000;19:1089-99. 